\title{
Clinical research protocol to evaluate the effectiveness and safety of individualized homeopathic medicine in the treatment and prevention of the COVID-19 epidemic
}

\author{
Darcus Zulian Teixeira ${ }^{1,2}$ \\ 1. Médico Homeopata, Doutor em Ciências Médicas, Pós-Doutorado, Coordenador e Pesquisador da Disciplina Eletiva de Fundamentos da Homeopatia \\ (MCM0773), Faculdade de Medicina da Universidade de São Paulo, São Paulo, SP, Brasil \\ 2. Coordenador Científico do Departamento Científico de Homeopatia da Associação Paulista de Medicina, São Paulo, SP, Brasil
}

Employing an integrative approach in the diagnosis and treatment of organic disorders (mental, general, and physical), homeopathy can act preventively in most acute or chronic diseases, moving forward to the process of their installation. To accomplish this intent, homeopathic medicines must stimulate a systemic and homeostatic reaction of the body against the various idiosyncrasies that predispose to illness, being indispensable to apply the principle of curative similarity according to the totality of characteristic symptoms of the diseased individuality (individualized medicine). ${ }^{1}$

In addition to its recognized application in chronic diseases, individualized homeopathy can also act in a resolutive or complementary way in acute cases, including is epidemics. However, to achieve this intent, a specific semiologic and therapeutic methodology cannot be disregarded.

In the case of epidemic diseases, which due to the virulence of their agents causes a common symptomatological picture in most susceptible individuals, individualized homeopathic medicine (homeopathic medicine of the epidemic genius) should bear similarity with the set of signs and symptoms of the patients affected by the different stages or phases of each epidemic outbreak. According to Samuel Hahnemann's approach, and per individual involvement, these individualized homeopathic medicines should be prescribed in isolation, in succession, or in alternation, but never as homeopathic complexes (mixtures of medicines in the same formula). ${ }^{2-4}$

After a survey of individualized homeopathic medicine(s) of the epidemic genius for the different stages of a given epidemic, the 'state of the art' of Hahnemannian homeopathic semiology, the application of therapeutic and/or large-scale prophylaxis should be accompanied by properly designed experimental and/ or observational studies so that the results can be analyzed according to the premises of modern clinical epidemiology, avoiding systematic errors (biases) and chances of contaminated isolated results. ${ }^{2-4}$

Unfortunately, in recent years, we have observed several homeopathic proposals for the treatment and/ or prophylaxis of dengue and influenza epidemics that contradict the homeopathic episteme, suggesting the application of complex homeopathic medicines 
(mixtures of homeopathic and/or isopathic medicines, which disregard previous pathogenetic experimentation and individualization according to the symptomatic totality that is characteristic of each stage of the current epidemic) for the entire population of a region, without using structured research protocols to assess the effectiveness and safety of such proposal..$^{2-4}$

The indiscriminate distribution of homeopathic medicines that promise to 'immunize' a collective group in the face of a given epidemic, without any notion of its efficacy, effectiveness, and safety, represents a risk to public health as it can induce the disregard of these people for the hygienic and prophylactic measures proven to be effective since they might feel 'protected' by these medicines.

Criticized by Hahnemann himself in the 19th century, empiricism is more serious today, a time when the scientific method is accessible and can be applied by all. Wrapped in countercultural obscurantism, many homeopathic physicians support their conduct only in their 'personal experience', disregarding the positive advances of contemporary science and rejecting knowledge indispensable to the development of homeopathic science.

On the other hand, in order to improve the homeopathic model in its various areas of activity, physicians and researchers need to adopt an impartial and prejudice-free posture, allowing rational and scientific homeopathy to have space to propose, discuss, and apply its research projects in medical schools and university hospitals, so that it can act in a complementary and adjuvant way in numerous health disorders.

Seeking to contemplate these objectives, in March 2020, we make available to the Brazilian and international homeopathic community the "Protocolo de pesquisa clínica para avaliar a eficácia e a segurança de medicamento homeopático individualizado no tratamento e na prevenção da epidemia de COVID-19", ${ }^{5}$ in which we discuss, in a broad way, the various aspects involving the homeopathic treatment of epidemics, including the current epidemic of COVID-19:

- Homeopathic treatment of epidemics: "Epistemological premises of the homeopathic model", "Guidelines for homeopathic treatment in epidemic diseases", and "Evidence of the effectiveness of homeopathy in epidemic diseases";

- Selection of individualized homeopathic medicines of the epidemic genius of COVID-19 for the 3 phases of the current epidemic: "COVID-19 epidemic", "Study of the epidemic genius of the current COVID-19 pandemic", "Homeopathic medicines of the epidemic genius for the prevention or treatment of mild to moderate disease", "Homeopathic medicines of the epidemic genius for the treatment of severe disease" and "Homeopathic medicines of the epidemic genius for the treatment of critical states";

- Ethical and scientific validation of the effectiveness and safety of possible drug hypotheses, so that they are used, a posteriori, in the treatment and prevention of the population on a large scale: "Ethical and bioethical aspects of research in human beings" and "Randomized, double-blind, placebo-controlled clinical trial”.

At the request of homeopathic researchers from several countries, the protocol has also been translated into English, so that it can be made available and applied by all ("Clinical research protocol to evaluate the effectiveness and safety of individualized homeopathic medicine in the treatment and prevention of the COVID-19 epidemic") ${ }^{6}$.

Since the publication of the Portuguese version, we have been seeking an opportunity to apply this protocol to patients hospitalized in wards and ICUs of public and private hospitals, disseminating it to colleagues and researchers from numerous educational and research institutions. However, we are still waiting for positive feedback from researchers who have shown interest in it.

\section{REFERENCES}

1. Teixeira MZ. Special Dossier: "Scientific Evidence for Homeopathy". Rev Assoc Med Bras. 2018;64(2):93-4. Available from: https://doi. org/10.1590/1806-9282.64.02.93.

2. Teixeira MZ. Homeopathy: a preventive approach to medicine? Int J High Dilution Res. 2009;8(29):155-72. Available from: http://highdilution.org/ index.php/ijhdr/article/view/360

3. Teixeira MZ. Homeopatia nas doenças epidêmicas: conceitos, evidências e propostas. Rev Homeopatia (São Paulo). 2010;73(1-2):36-56. Available from: http://revista.aph.org.br/index.php/aph/article/view/36.

4. Teixeira MZ. Isoprophylaxis is neither homeoprophylaxis nor homeopathic immunization, but isopathic immunization unsupported by the homeopathic epistemological model: a response to Golden. Int J High Dilution Res. 2014;13(46):54-82. Available from: http://highdilution.org/index. php/ijhdr/article/view/707.

5. Teixeira MZ. Protocolo de pesquisa clínica para avaliar a eficácia e a segurança de medicamento homeopático individualizado no tratamento e na prevenção da epidemia de COVID-19. São Paulo: AMHB; APH; 2020. 62p. Available from: https://pesquisa.bvsalud.org/portal/resource/en/ biblio-1087238.

6. Teixeira MZ. Clinical research protocol to evaluate the effectiveness and safety of individualized homeopathic medicine in the treatment and prevention of the COVID-19 epidemic. São Paulo: AMHB; APH; 2020. 60p. Available from: https://pesquisa.bvsalud.org/portal/resource/en/ biblio-1088044 